\title{
Avaliação fitoquímica, físico-química e atividades antioxidante, hemotóxi- ca e antibacteriana do extrato de Protium spruceanum (Benth.) Engl
}

\author{
Antonio Carlos Pereira de Menezes Filho ${ }^{a *(0)}$, Mariana Chaves Santos ${ }^{a}{ }^{\circledR}$, \\ Carlos Frederico de Souza Castro ${ }^{a}$ \\ a Instituto Federal Goiano, Campus Rio Verde, Goiás, Brasil \\ *Autor correspondente (astronomoamadorgoias@gmail.com)
}

\section{N F O}

Keywords

Protium spruceanum

Screening phytochemical

Escherichia coli;

Staphylococcus aureus

\section{Palavras-chaves}

Protium spruceanum Prospecção fotoquímica Escherichia coli Staphylococcus aureus

\begin{abstract}
A B S T R A C T
Phytochemical, physicochemical evaluation and antioxidant, hemotoxic and antibacterial activities of the extract from Protium spruceanum (Benth.) Engl. Protium spruceanum is one 146 species in the genus Protium. It's considered medicinal plant by the field and scientific population. The objective this study was evaluates the phytochemistry, physicochemical and antioxidant, hemotoxic and antibacterial activities of the hydroethanolic extract from $P$. spruceanum resin. It's noteworthy the results presented this study, showed numerous phytochemicals class with positive results, soluble solids with $1.15 \%$, refractive index of $1.584, \mathrm{pH}$ of 5.63 , relative density of $0.9517 \mathrm{~g} \mathrm{~mL}^{-1} 20^{\circ} \mathrm{C}, \mathrm{IC}_{50}$ of $275.14 \mu \mathrm{g} \mathrm{mL}^{-1}$ of $\mathrm{DPPH}$, total phenolics of $9.96 \mathrm{mg} \mathrm{GAE} 100 \mathrm{~g}^{-1}$, and yield of $6.61 \%$. Positive hemolytic activity, and in particular, efficiency in antibacterial activity with inhibition halos from $19.13 \mathrm{~mm}$ Staphylococcus aureus, $14.07 \mathrm{~mm}$ Salmonella typhimurium, and $17.51 \mathrm{~mm}$ Salmonella enteritidis, and low inhibition Escherichia coli $9.18 \mathrm{~mm}$. The hydroethanolic extract of Protium spruceanum resin showed exceptional results as an antioxidant and antibacterial agent.
\end{abstract}

\section{R E S U M O}

Protium spruceanum é uma das 146 espécies do gênero Protium, considerada como medicinal pela população do campo e no meio científico. O objetivo deste estudo foi avaliar a fitoquímica, físicoquímica e as atividades antioxidantes, hemotóxica e antibacteriana do extrato hidroetanólico da resina de $P$. spruceanum. Destaca-se que os resultados apresentados neste estudo apresentaram inúmeras classes fitoquímicas com resultados positivos, sólidos solúveis com 1,15\%, índice de refração de 1,584, pH de 5,63, densidade relativa de $0,9517 \mathrm{~g} \mathrm{~mL}^{-1} 20{ }^{\circ} \mathrm{C}, \mathrm{CI}_{50}$ de $275,14 \mu \mathrm{g} \mathrm{mL}^{-1}$ de $\mathrm{DPPH}$, fenólicos totais de $9,96 \mathrm{mg}$ EAG $100 \mathrm{~g}^{-1}$, e rendimento de 6,61\%. Atividade hemolítica positiva, em especial, eficiência na atividade antibacteriana com halos de inibição de 19,13 $\mathrm{mm}$ para Staphylococcus aureus, de 14,07 $\mathrm{mm}$ para Salmonella typhimurium, e de 17,51 mm para Salmonella enteritidis, e baixa inibição para Escherichia coli de $9,18 \mathrm{~mm}$. O extrato hidroetanólico da resina de Protium spruceanum demonstrou resultados excepcionais como agente antioxidante e antibacteriano. 


\section{INTRODUÇÃO}

A família Burseraceae é formada exclusivamente por espécies arborícolas e arbustos em áreas tropicais da América do Sul, Malásia e África. O gênero Protium Burm. f. apresenta aproximadamente cerca de 146 espécies, deste total, nove são neotropicais. A grande maioria das espécies habita áreas de sub-bosque na floresta úmida primária e em terra firme (Machado et al., 2003; Vieira et al., 2010).

O principal centro de diversidade está no bioma Amazônico onde são identificadas 73 espécies, sendo 42 endêmicas dessa região. A espécie Protium spruceanum (Benth.) Engler, apresenta porte arbóreo com dossel, ou arbórea secundária, seletiva higrófita e com síndromes de entomofilia e ornitocoria, onde alguns indivíduos foram registrados em estudo apresentando altura de 20 metros. Entre a população, a espécie é conhecida por "breu-branco, amescla, almecegueira ou resina mesca". O auge das inflorescências são nos meses de setembro a novembro com frutificação entre outubro a março; os frutos são do tipo baga subglobosa, de superfície lisa e brilhante, com coloração avermelhado, contendo de 1 a 2 sementes cinzentas envoltas por arilo fino, carnudo e adocicado. Pode ocorrer deposição de resina na área externa do fruto. Naturalmente, os frutos servem de alimento para pássaros, que promovem a dispersão (zoocórica) (Vieira et al., 2010). De acordo com Vieira e Carvalho (2008), a espécie é utilizada em áreas de reflorestamento heterogêneo destinado a recuperação da vegetação de áreas ciliares degradadas.

$P$. spruceanum é encontrado além do bioma Amazônico, na Mata Atlântica e no domínio Cerrado principalmente no estado de Goiás. Alguns estudos apresentam diversidade ecológica nos estados de Minas Gerais, algumas áreas dos estados da Bahia, Mato Grosso do Sul e São Paulo, em áreas de florestas tropicais, de matas ciliares, em ambientes ripários e em áreas de brejo (Oliveira Filho; Ratter, 1995; Fajardo et al., 2009). A espécie é aromática, com resina oleosa, que quando encontra o oxigênio do ambiente, cristaliza no tronco apresentando coloração esbranquiçada. A resina apresenta uso fitoterápico no tratamento dos sintomas da gripe, na analgesia, como cicatrizante e expectorante, bem como é utilizada na indústria de vernizes, na calafetagem, e como flavorizante na indústria de perfumaria (Machado et al., 2003).

Os vegetais produzem naturalmente compostos pertencentes aos metabólitos secundários, apresentando inúmeras ações biológicas, sendo amplamente estudados pelas indústrias farmacêutica, agrícola e de biotecnologia. Os metabólitos secundários apresentam em inúmeros estudos, importantes atividades com valor comercial. O estudo fitoquímico preliminar tem um grande papel para o conhecimento das classes constituintes nas espécies vegetais, onde após a identificação, inicia o processo de extração de determinadas classes de maior interesse (Simões; De Almeida, 2015). A resina é um dos compostos desse metabolismo, apresentando em sua constituição a $\alpha$ - e $\beta$-amirinas (Rodrigues et al., 2013), sabineno e $\beta$-cariofileno como compostos majoritários nos óleos essenciais das folhas, resina e galhos (Machado et al., 2003). O extrato etanólico dos galhos apresenta importante ação antimicrobiana, testada em 19 isolados de bactérias patogênicas (Amparo et al., 2018).

Inúmeros extratos vegetais apresentam atividade antioxidante na redução de radicais livres como o oxigênio singleto. Pessuto et al. (2009) apresentam que, extratos vegetais ricos em compostos fenólicos demonstram importante atividade antioxidante, atuando como sequestradores de radicais livres e como quelantes de metais. Vários agentes oxidantes agem na depleção de biomoléculas, principalmente no DNA, podendo desencadear vários tipos de cânceres, bem como estão envolvidos nas doenças de Parkinson e Alzheimer (Conde et al., 2017; Lemes et al., 2017; Zimmermann; Kirsten, 2008). Conforme Conde et al. (2017) os agentes antioxidantes podem atuar em múltiplos mecanismos biológicos, em dependência do sistema de reação ou fonte de radicais ou oxidante avaliado.

Outros usos de importância sobre o estudo de extratos vegetais é na ação promotora da inibição do crescimento de fungos, bactérias e vírus que causam sérios problemas tanto nos estudos de espécies vegetais de uso agrícola, como na produção de fitofármacos no tratamento de doenças fúngicas, bacterianas e virais em humanos e animais. Visto que, várias bactérias ao longo dos anos vêm apresentando resistência aos antibióticos comerciais, como Staphylococcus aureus, Staphylococcus epidermidis e Escherichia coli (García et al., 2019).

$\mathrm{Na}$ busca por novos fitofármacos ativos, vem sendo constantemente estudados como proposta de substituição aos fármacos sintéticos de referência que já não estão apresentando efetiva atividade de inibição. O estudo das espécies vegetais no Brasil, em especial no domínio Cerrado vem como proposta, auxiliar no estudo fitoterápico com alto potencial fitomedicinal encontrado nas inúmeras fitofisionomias desse ambiente natural.

$\mathrm{O}$ trabalho teve por objetivo avaliar à 
fitoquímica, físico-química e as atividades antioxidantes, hemotóxica e antibacteriana do extrato hidroetanólico da resina de Protium spruceanum.

\section{MATERIAL E MÉTODOS}

A resina foi coletada nas cascas dos troncos e de raízes descobertas em indivíduos de $P$. spruceanum, com auxílio de uma faca inox. O material foi mantido em frasco plástico hermético resfriado em uma embalagem com isolamento térmico. A coleta foi realizada no mês de abril de 2020 em uma area de mata ciliar localizada no município de Rio Verde - GO, Brasil, nas seguintes coordenadas geográficas: $17^{\circ} 42^{\prime} 59.5^{\prime}$ 'S $50^{\circ} 53$ '27.3' 'W. A área de coleta apresenta fitofisionomia de mata ciliar e brejo. A espécie foi identificada pelo $\mathrm{MSc}^{\circ}$ Biólogo Antonio Carlos Pereira de Menezes Filho. Uma exsicata foi herborizada e depositada no Herbário do laboratório de Sistemática Vegetal do IF Goiano, Campus Rio Verde, com o seguinte Voucher HRV 1015.

A resina foi triturada em um processador de alimentos, obtendo-se assim um pó fino e homogêneo. O extrato bruto hidroetanólico foi obtido via turbólise na proporção de $40 \mathrm{~g}$ do pó para $200 \mathrm{~mL}$ de uma solução hidroetanólica $70 \%$ $(v / v)$.

$\mathrm{O}$ extrato permaneceu em um frasco âmbar em repouso na geladeira por 24 horas a $4{ }^{\circ} \mathrm{C}$, sem presença de luz. Após este período, o extrato foi transferido para um frasco Erlenmeyer e submetido a ondas de ultrassom, em banho de ultrassom (Eco-Sonics, Mod. Q3,0/40A), por 30 minutos em local ao abrigo da luz. O extrato foi novamente transferido para o frasco âmbar e armazenado na geladeira a $4{ }^{\circ} \mathrm{C}$ por 72 horas. Em seguida, o extrato bruto foi filtrado em papel de filtro. $\mathrm{O}$ sobrenadante foi concentrado em rotaevaporador rotativo à pressão negativa (Fisatom, Mod. 801), até completa eliminação do álcool etílico. Em seguida, foi congelado a $-10^{\circ} \mathrm{C}$ e posteriormente liofilizado. $\mathrm{O}$ extrato em pó foi armazenado em frasco de vidro cor âmbar, identificado e mantido em geladeira a $4{ }^{\circ} \mathrm{C}$ até análises conforme descrito por Oliveira et al. (2014).

Foram realizadas análises colorimétricas e de precipitação para as classes de compostos fenólicos, açúcares redutores, não redutores, taninos, flavonoides, antraquinonas, cumarinas, ácidos orgânicos, catequinas, esteróides e triterpenos, saponinas espumídica e hemolítica, glicosídeos cardiotônicos, duplas olefínicas, benzaquinonas, naftaquinonas e fenantraquinonas, alcaloides e depsídeos e depsidonas conforme descrito por Menezes Filho e Castro (2019), glicosídeos cianogênicos, conforme descrito por Rodrigues et al. (2009), polissacarídeos, purinas, resinas e sesquiterpenolactonas conforme descrito por Simões e De Almeida (2015).

Os reagentes utilizados para os testes fitoquímicos foram de grau (P.A - ACS) das marcas (Synth, Anidrol, Dinâmica, SigmaAldrich, Alphatec, Vetec, Inlab, Cromoline, Neon, Isofar, Proquímicos, Êxodo Científica, Qhemis, Quimex, Impex, LS Chemicals).

Os resultados foram comparados com o grupo controle (branco). Para a intensidade da reação foi utilizado teste de cruzes $(+)$ fraco positivo, $(++)$ moderado positivo e $(+++)$ fortemente positivo, e (-) negativo (Oliveira et al., 2014). A determinação da atividade hemolítica seguiu conforme descrito por Ramos et al. (2020). Em três tubos Falcon cônicos (Sarstedt) de $50 \mathrm{~mL}$, foram acrescidos com $5 \mathrm{~mL}$ de solução fisiológica $\mathrm{NaCl}$ concentração $0,9 \%$ (Arboreto) e três tubos Falcon cônicos como controle positivo contendo água destilada e sangue. $\mathrm{O}$ ensaio foi realizado nas seguintes concentrações 50;100; 150; 250; 500; $750 ; 1000 \mu \mathrm{g} \mathrm{mL}^{-1}$ de extrato hidroetanólico da resina de $P$. spruceanum. As amostras foram incubadas em temperatura de $25{ }^{\circ} \mathrm{C}$ em banho ultratermostatizado (Solab, Mod. SL 152-I) por 15 mim. Em seguida, as amostras foram centrifugadas (Solab, Mod. SL-700) a 3.000 RPM durante 20 minutos. Em seguida, o sobrenadante foi analizado em espectrofotômetro UV-Vis no comprimento de ondas em $540 \mathrm{~nm}$ em absorbância, utilizando cubeta de quartzo com campo óptico de $1 \mathrm{~cm}$. O percentual hemolítico foi determinado com o Abs do controle positivo como $100 \%$. O porcentual hemolítico foi determinado conforme equação 3 , proposta por Dacie et al. (1975).

$\% \mathrm{Hem}=\left(\mathrm{Abs}_{\text {amostra }}\right) * 100 /\left(\mathrm{Abs}_{\text {controle }}\right)$

Após o ensaio hemolítico, foram realizadas imagens microscópicas, utilizando microscópio óptico (Global Optics, Mod. NO215B) com objetivas planacromática 4,10 e 40 X, e câmera acoplada ao microscópio (GX) Full HD 30 FPS. Uma alíquota de $20 \mu \mathrm{L} \mathrm{mL}^{-1}$ foi adicionado a 150 $\mu \mathrm{L} \mathrm{mL} \mathrm{mL}^{-1}$ do concentrado de hemácias a $5 \%$. O tempo foi avaliado em 5 e 10 minutos. Como controle negativo foi utilizado solução de hemácias a 5\% e solução hidroetanólica $70 \%$.

Os parâmetros organolépticos e físico-químicos para sólidos totais e índice de refração (Hanna Instruments, Mod. HI96800), foram avaliados conforme descrito por Domínguez et al. (2019), e López et al. (2019). O pH foi determinado através de um pHmetro digital de 
bancada (Lucadena, Mod. 210-P), com uma alíquota de $50 \mathrm{~mL}$ de extrato bruto. A densidade relativa foi determinada utilizando um picnômetro de $1 \mathrm{~mL}$, conforme descrito por Alarcón et al. (2019). O resultado foi expresso em $\mathrm{g} \mathrm{mL}^{-1}$ a 20 ${ }^{\circ} \mathrm{C}$. Uma varredura foi realizada entre os comprimentos de ondas 200 a $800 \mathrm{~nm}$ em espectrofotômetro UV-Vis (Bel Photonics, Mod. M-51) por absorbância utilizando cubeta de quartzo a partir do extrato bruto $1 \mathrm{~mL}$, afim de descrever as possíveis classes metabólicas presentes conforme descrito por García et al. (2019). O rendimento de extrato seco bruto foi calculado conforme descrito por Alves et al. (2011). Calculado a partir da relação da massa de extrato seco por massa da droga vegetal expresso em percentagem conforme equação 1 (Balança analítica, Marte, Mod. AW 220).

$$
\begin{gathered}
\text { Rend. }(\%)=(g \text { Ext Sec/Drog Veg }) \\
* 100 \text { Eq. }[1]
\end{gathered}
$$

Onde:

$g$ Ext Sec $=(\mathrm{g})$ do extrato seco, $g$ Drog Veg $=(\mathrm{g})$ droga vegetal.

A atividade redutora do radical livre, foi determinada utilizando 2'2-difenil-1-picrilhidrazil (DPPH - P.A - ACS) (Sigma-Aldrich), através do método descrito por Conde et al. (2019). Em placa de 96 poços, uma alíquota de $75 \mu \mathrm{L} \mathrm{mL}^{-1}$ de amostra do extrato, foi adicionada com $150 \mu \mathrm{L}$ $\mathrm{mL}^{-1}$ de uma solução etanólica de DPPH $(100 \mu \mathrm{g}$ $\mathrm{mL}^{-1}$ ). Em seguida, foi incubado a $25{ }^{\circ} \mathrm{C}$ por 60 minutos. Logo após, a placa foi levada para um espectrofotômetro UV-Vis leitor de microplacas (Polaris, Mod. EE) no comprimento de ondas em $517 \mathrm{~nm}$. Foi utilizada uma solução etanólica de ácido ascórbico (P.A - ACS) (Synth, pureza de 99-100\%) como controle positivo para redução do radical DPPH $\left(25 \mu \mathrm{g} \mathrm{mL}^{-1}\right)$. A concentração de inibição $\left(\mathrm{CI}_{50}\right)$ foi determinada através de sucessivas concentrações seriadas da amostra (5 a $1000 \mu \mathrm{g} \mathrm{mL}^{-1}$ ) através de uma análise de regressão linear. Os resultados foram expressos em porcentagem de redução do radical livre DPPH pelo extrato bruto da resina de $P$. spruceanum, conforme equação 2.

$$
\% \text { Red. }=\frac{A 0-A E}{A 0} * 100 E q .[2]
$$

Onde:

A0 é a solução etanólica de DPPH; e AE solução hidroetanólica do extrato resinoso + solução de DPPH.

Os compostos fenólicos totais foram determinados pelo método de Folin-Ciocalteu (P.A - ACS) (Sigma-Aldrich, pureza de 98\%) conforme descrito por Fernández et al. (2017). A solução de Folin-Ciocalteu foi preparada a partir de $10 \mathrm{~mL}$ do reativo, diluído em $100 \mathrm{~mL}$ de água destilada. Em seguida, foi preparada uma solução aquosa de carbonado de sódio anidro (P.A - ACS) (Dinâmica, pureza 98-100\%) na concentração $7,5 \%(\mathrm{~m} / \mathrm{v})$.

Uma curva padrão foi preparada com $500 \mathrm{mg}$ de ácido gálico (P.A - ACS) (Dinâmica, pureza de 98-100\%). Em seguida, foi dissolvido em $20 \mathrm{~mL}$ de água destilada. A solução foi transferida para um balão volumétrico de $50 \mathrm{~mL}$, completado com água destilada. A partir da solução estoque, em balão volumétrico de $100 \mathrm{~mL}$, alíquotas entre 1 a 5 $\mathrm{mL}$ foram transferidas, e em seguida, acrescidas com água destilada. As diluições correspondem as seguintes concentrações $10,20,30,40$ e $50 \mathrm{mg}$ $100 \mathrm{~mL}^{-1}$ expresso em equivalente ao ácido gálico (EAG).

Em tubos de ensaios, foram adicionados $200 \mu \mathrm{L}$ $\mathrm{mL}^{-1}$ do extrato, com $10 \mathrm{~mL}$ da solução aquosa de Folin-Ciocalteu e 1,8 mL de água destilada. A solução foi agitada por 10 segundos em Vortex (Prolab), e deixada em descanso por 5 minutos em local protegido da luz. Logo após, foi adicionado 8 $\mathrm{mL}$ da solução aquosa de carbonado de sódio $7,5 \%$, e em seguida, agitado em Vortex por 1 minuto. As amostras foram mantidas em local escuro por 1 hora. Em seguida, foi realizada a leitura em espectrofotômetro UV-Vis (Bel Photonics, Mod. M-51) no comprimento de ondas em $765 \mathrm{~nm}$. O mesmo foi realizado para as soluções da curva padrão.

A atividade antibacteriana foi realizada conforme descrito por Fernández et al. (2017). Foram utilizadas culturas de bactérias dos gêneros Staphylococcus aureus ATCC 9891, Salmonella sorovar Typhimurium ATCC 14028, Salmonella sorovar Enteritidis ATCC 13076 e Escherichia coli ATCC 8739. As bactérias foram doadas pelo banco genético de microorganismos da Universidade Federal de Goiás - UFG, Campus Samambaia, Goiânia, Goiás, Brasil. Inicialmente colônias foram suspendidas em $50 \mathrm{~mL}$ de uma solução aquosa de caldo peptona bacteriológica (PB - Kasvi) em frasco Erlenmeyer $125 \mathrm{~mL}$ esterilizado. E logo em seguida, incubado a $36{ }^{\circ} \mathrm{C}$, por 48 horas (SolidSteel, Mod. SSD). Após fase de crescimento, alíquotas de $5 \mathrm{~mL}$ foram coletadas e distribuídas em placas de Petri contendo meio Ágar Contagem de Placas (ACP - Kasvi) esterilizado, e homogeneizadas com auxílio de uma alça de Drigalski após flambagem. As placas foram incubadas a $36^{\circ} \mathrm{C}$ por 24 horas.

Foram selecionadas cinco colônias coletadas com uma alça de platina flambada, e transferiu-se para Erlenmeyers de $125 \mathrm{~mL}$ contendo $50 \mathrm{~mL}$ de 
caldo peptona bacteriológica, em seguida foram incubados entre 35 a $37{ }^{\circ} \mathrm{C}$ por 24 a 36 horas em incubadora com agitação orbital a $100 \mathrm{rpm}$, até obter turbidez adequada conforme a escala 0.5 de McFarland. Após determinação da turbidez ideal, entre 1 a $2 \times 10^{8} \mathrm{UFC} \mathrm{mL}^{-1}$ uma alíquota de $5 \mathrm{~mL}$ foi coletada e transferida para placas de Petri contendo meio ACP. Em seguida, a solução foi homogeneizada com alça de Drigalski após flambagem.

A avaliação da atividade antimicrobiana foi realizada através do método de difusão em poços. $\mathrm{Na}$ placa de Petri foram realizados pequenos poços com $9 \mathrm{~mm}$ de diâmetro na superfície do meio. Em cada placa foram realizados 4 poços, onde foi aplicado $100 \mu \mathrm{L} \mathrm{mL}^{-1}$ para o $1^{\circ}$ poço: Ciprofloxacina $500 \mathrm{mg}$ (La Santé), como controle positivo, no $2^{\circ}$ poço: Azitromicina $500 \mathrm{mg}$ (Eurofarma), como controle positivo, no $3^{\circ}$ poço: água destilada estéril como controle negativo, e no $4^{\circ}$ poço: extrato hidroetanólico da resina de $P$. spruceanum na concentração de $20 \%(\mathrm{~m} / \mathrm{v})$. Os controles positivos foram diluídos em $50 \mathrm{~mL}$ de água destilada estéril na seguinte concentração (500 mg $100 \mathrm{~mL}^{-1}$ ).

Após a aplicação, as placas foram mantidas por 30 minutos em câmara de fluxo laminar a $25^{\circ} \mathrm{C}$, e em seguida incubadas a $37{ }^{\circ} \mathrm{C}$ por 24 a 36 horas. Após este período, a leitura foi realizada utilizando paquímetro digital (Digimess, Mod. $100.174 \mathrm{NL}$, resolução de $0,01 \mathrm{~mm} / .0005$ " com erro de $0,001 \mathrm{~mm}$ ), e o diâmetro do halo da zona de inibição determinado, considerando o diâmetro do orifício.

Todos os ensaios foram realizados em triplicata, seguido de \pm desvio padrão. O software estatístico utilizado foi o PAST 3 (versão livre, 2019).

\section{RESULTADOS E DISCUSSÃO}

A resina de $P$. spruceanum foi coletada em 10 indivíduos, apresentando coloração natural branca, sendo produzida nas raízes, tronco e galhos, exalando aroma natural no ambiente circundante aos indivíduos na área de mata de galeria natural, sendo esta, característica da presença desta espécie. Os indivíduos de $P$. spruceanum coletados neste estudo no mês de abril, coincidiram com o período de frutificação para este ambiente de Cerrado goiano. Já Vieira e Carvalho (2008) descrevem o período de frutificação entre outubro a março para $P$. spruceanum. No estudo de Vieira et al. (2010) os pesquisadores discutem sobre o pico de frutificação ser no mês de novembro coincidindo com o período chuvoso, que aumenta a taxa de germinação.

Na figura 1, está apresentado um indivíduo de $P$. spruceanum, com produção do exsudato (resina) em uma raiz descoberta em ambiente de Cerrado natural.

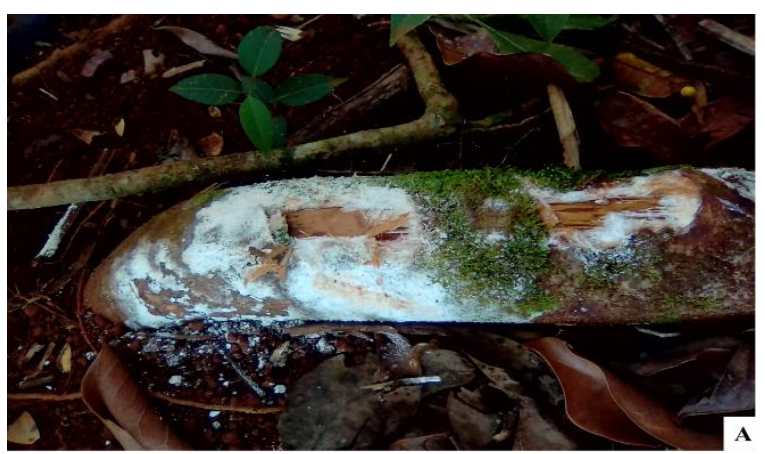

Figura 1 - (A) Raíz descoberta naturalmente de $P$. spruceanum com exsudato (resina) em cor branca.

A partir do período chuvoso foram obtidas quantidades significativas de resina cerca de $35 \mathrm{~g}$ através do processo de escarificação, sendo coletada a partir das raízes descobertas (Figura 1), e dos troncos. Entretanto, a resina pode ser coletada em qualquer período do ano, principalmente na época de chuva, onde o vegetal produz maior conteúdo de exsudato (Figura 1).

Na tabela 1, estão apresentados os parâmetros físico-químicos e bioativos a partir do extrato hidroetanólico da resina de $P$. spruceanum.

Tabela 1 - Características físico-químicas e bioativas do extrato hidroetanólico da resina de P. spruceanum.

\section{Parâmetros}

Características organolépticas

Sólidos solúveis (\%)

Índice de refração

$\mathrm{pH}$

Densidade relativa $\left(\mathrm{g} \mathrm{mL}^{-1}\right) 20{ }^{\circ} \mathrm{C}$

DPPH CI ${ }_{50}\left(\mu \mathrm{g} \mathrm{mL}^{-1}\right)$

Compostos fenólicos totais (mg EAG $100 \mathrm{~g}^{-1}$ )

Rendimento de extrato seco (\%)

\section{EHR*}

Líquido marrom cristalino, aromático resinoso, límpido, não oleoso ao tato.

$$
\begin{gathered}
1,15 \pm 0,06 \\
1,584 \pm 0,08 \\
5,63 \pm 0,01 \\
0,9517 \pm 0,01 \\
275,14 \pm 0,13 \\
9,96 \pm 0,13 \\
6,61 \pm 0,19
\end{gathered}
$$

*EHR $=$ Extrato hidroetanólico da resina de $P$. spruceanum. 
As características organolépticas para o extrato bruto hidroetanólico apresentou-se como um líquido marrom cristalino, aromático resinoso, límpido, não oleoso ao tato. O conteúdo de sólidos solúveis totais foi de 1,15\% (Tabela 1). Os sólidos solúveis totais representam o conteúdo de material orgânico volátil e inorgânico da solução de extrato. Outros estudos avaliando extratos, em diversas espécies vegetais, como no estudo de López et al. (2019) os pesquisadores encontraram resultado para sólidos totais de 1,03\% para $100 \mathrm{~mL}$ do extrato aquoso da semente de Swietenia humilis.

$\mathrm{O}$ extrato de $P$. spruceanum demonstrou ser fracamente ácido com pH de 5,63 (Tabela 1). O $\mathrm{pH}$ varia conforme o extrato vegetal de inúmeras plantas. Domínguez et al. (2019) encontraram pH de 6,19 para o extrato etanólico das folhas, e de 6,33 para o extrato dos bulbos de Allium schoenoprasum. $\mathrm{O} \mathrm{pH}$ levemente ácido em extratos, pode estar relacionado a classe de compostos de natureza fenólica (Domínguez et al., 2019). O extrato hidroetanólico da resina de $P$. spruceanum apresentou densidade relativa de $0,9517 \mathrm{~g} \mathrm{~mL}^{-1}$ conforme observa-se na (Tabela 1). $\mathrm{O}$ extrato apresentou efetiva e especial atividade antioxidante na redução do radical livre $\mathrm{DPPH}$, com $\mathrm{CI}_{50}$ de $275,14 \mu \mathrm{g} \mathrm{mL}^{-1}$ (Tabela 1).

Em vários estudos, é possível verificar que extratos vegetais apresentam bons resultados antioxidantes na redução do radical livre, inclusive através do modelo DPPH amplamente avaliado. Comparando com outros extratos vegetais, Conde et al. (2019), avaliaram o extrato etanólico de pimentão (Capsicum annum), onde os pesquisadores obtiveram atividade antioxidante com $\mathrm{CI}_{50}$ de $343,00 \mu \mathrm{g} \mathrm{mL}^{-1}$ na redução do radical DPPH. Os compostos fenólicos totais foram de 9,96 mg EAG $100 \mathrm{~g}^{-1}$ de resina (Tabela 1). O conteúdo de fenólicos totais na resina é considerado baixo, em comparação com os extratos das folhas e galhos como avaliado por Amparo (2016), onde o pesquisador encontrou para os extratos etanólicos das folhas e galhos de $P$. spruceanum resultados de 74,31 e de $103,06 \mathrm{mg}$ EAG $100 \mathrm{~g}^{-1}$.

$O$ rendimento encontrado para o extrato hidroetanólico da resina de P. spruceanum foi de $6,61 \%$ para a resina dos galhos e das raízes descobertas (Tabela 1). Amparo (2016) encontrou rendimento de $16,03 \%$ para o extrato bruto etanólico das folhas e para os galhos de $9,60 \%$ para $P$. spruceanum. Conforme Sultana et al. (2009), a diferença de rendimento entre os diversos órgãos de um vegetal se deve a sua disponibilidade resultante da variedade da composição química no vegetal, bem como a época de coleta do material biológico.

$\mathrm{Na}$ tabela 2, estão apresentados os resultados para fitoquímica a partir do extrato hidroetanólico

da resina de $P$. spruceanum.

Foi observada uma grande quantidade de compostos do metabolismo secundário a partir do extrato hidroetanólico da resina de $P$. spruceanum, com resultados positivos.

As provas de reação para os ensaios fitoquímicos realizados no extrato hidroetanólico de $P$. spruceanum, apresentaram resultados positivos para compostos fenólicos, corroborando com o ensaio de compostos fenólicos totais por reativo de Folin-Ciocalteau realizado conforme descrito na (Tabela 1), além deste, foram observados resultados positivos para açúcares redutores, taninos, flavonoides, antraquinonas, cumarinas, ácidos orgânicos, catequinas, esteróides e triterpenos, saponinas hemolíticas, esta, corroborando com o ensaio hemolítico em suspensão de hemácias (Figura 2), para glicosídeos cardíacos e cianogênicos, duplas olefínicas, benzoquinonas, naftoquinonas e fenantraquinonas, alcaloides, depsídeos e depsidonas, purinas, resinas e sesquiterpenolactonas conforme apresentado na (Tabela 2). A triagem fitoquímica demonstrou que o extrato hidroetanólico da resina apresenta inúmeros compostos, em especial, e de grande importância principalmente para a farmacologia.

Tabela 2 - Prospecção fitoquímica do extrato hidroetanólico da resina de P. spruceanum coletados em área de Cerrado em Rio Verde - Goiás, Brasil.

\begin{tabular}{lc}
\hline Metabólitos & Resultados \\
\hline Compostos fenólicos & +++ \\
Açúcares redutores & ++ \\
Açúcares não redutores & - \\
Taninos & $\mathrm{Vd}$ \\
Flavonoides & +++ \\
Antraquinonas & ++ \\
Cumarinas & + \\
Ácidos orgânicos & +++ \\
Catequinas & ++ \\
Esteroides e triterpenos & +++ \\
Saponins espumídica & - \\
Saponina hemolítica & +++ \\
Glicosídeos cardíacos & +++ \\
Glicosídeos cianogênicos & ++ \\
Duplas olefinas & +++ \\
Benzaquinonas, naftaquinonas e fenan- & ++ \\
traquinonas & \\
Alcaloides & +++ \\
Depsídeos e depsidonas & +++ \\
Polissacarídeos & - \\
Purinas & +++ \\
Resinas & +++ \\
Sesquiterpenolactonas & ++ \\
\hline (+++) fortemente positivo, (++) moderadamente & positivo, (+) \\
fracamente positivo, (-) negativo. (Vd) taninos catéquicos e $(\mathrm{Az})$ \\
taninos condensados. & \\
&
\end{tabular}


Amparo (2016) encontrou para o extrato bruto das folhas e galhos de $P$. spruceanum as seguintes classes de compostos secundários: cumarinas, flavonoides, taninos, terpenóides e ácidos graxos. Estudos fitoquímicos preliminares para o gênero Protium, já demonstraram a presença de compostos esteroidais, terpenos (mono- e triterpenos), cumarinas, ligninas, fenilpropanoides e flavonoides (Magalhães et al., 2006; Adfa et al., 2013). Para a espécie de $P$. spruceanum através das análi- ses em CG-EM e HPLC a partir da análise do extrato dos galhos, foram observados alguns ésteres de ácidos graxos, terpenos, flavonoides e taninos no estudo realizado por Amparo et al. (2018), corroborando com os resultados apresentados neste estudo.

Na figura 2, está apresentada a porcentagem hemolítica do extrato hidroetanólico $70 \%$ da resina extraída das cascas do tronco e raiz de $P$. spruceanum.

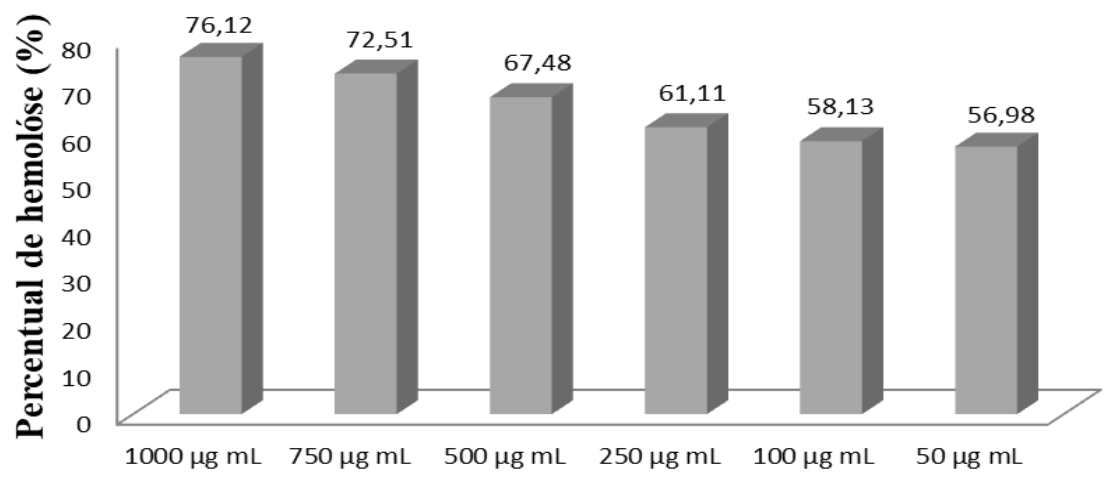

Conc. $\mu \mathrm{g} \mathrm{mL}$ de extrato resinoso

Figura 2 - Percentual hemolítico do extrato resinoso hidroetanólico $70 \%$ de $P$. spruceanum em diferentes concentrações expressos em $\mu \mathrm{g} \mathrm{mL} \mathrm{L}^{-1}$.

Conforme se observa na figura 2 , o extrato resinoso de $P$. spruceanum apresenta atividade hemolítica considerada alta em todas as concentrações entre 76 a $56 \%$. Devido a falta de dados para cunho comparativo no gênero Protium, os resultados deste estudo, foi comparado com outros extratos, como nos estudos de Sousa et al. (2018), onde os pesquisadores observaram atividade hemolítica de $63,88 \%$ na maior concentração de $400 \mu \mathrm{g} \mathrm{mL}^{-1}$ para o extrato hidroetanólico $70 \%$ das cascas do caule de Ziziphus joazeiro. Conforme Nofiani et al. (2011), e Ramos et al. (2020), processos hemolíticos acima de $40 \%$ são considerados altos e inferior a esse valor, considerado baixo.

$\mathrm{Na}$ figura 3, estão apresentadas micrografias ópticas do processo de hemólise do tecido hematopoiético em suspendido de eritrócitos humanos a $5 \%$ após o período de 5 e 10 minutos da administração do extrato hidroetanólico da resina de $P$. spruceanum.

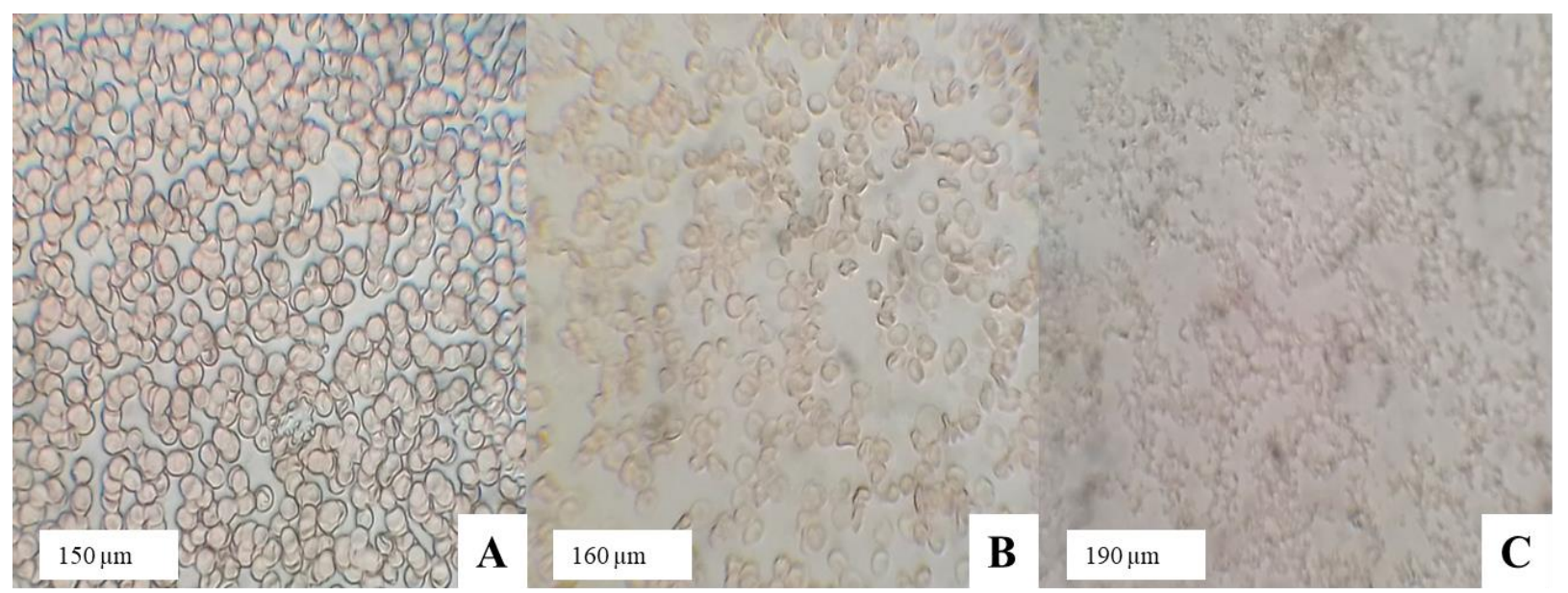

Fonte: Pesquisa, (2020).

Figura 3 - Micrografia óptica da suspenção de eritrócitos humanos a 5\% (v/v) em solução salina a $0,85 \%$ $(\mathrm{m} / \mathrm{v})$. Em (A) concentrado de eritrócitos normocíticos. Em $(\mathbf{B})$ tempo de 5 minutos após adição de $20 \mu \mathrm{L}$ $\mathrm{mL}^{-1}$ de extrato resinoso de $P$. spruceanum. Em $(\mathbf{C})$ tempo de 10 minutos após adição de $20 \mu \mathrm{L} \mathrm{mL}^{-1}$ de extrato resinoso de $P$. spruceanum. 
Como observado na tabela 2, não foram observados a presença de saponinas espumídicas, entretanto, foram observadas também a presença de saponinas hemolíticas conforme se observa na (Figura 3). A ação eritrocitária ocorreu entre 5 a 10 minutos, onde com 10 minutos houve completa hemólise com liberação de hemoglobina no meio extracelular dos eritrócitos. A concentração empregada neste estudo demonstrou apresentar toxicidade no tecido hematopoiético. Conforme Souza et al. (2018), a interação das moléculas com características hemolíticas do extrato, que ocorre com os esteróis constituintes da membrana do eritrócito, leva a formação de poros na membrana, causando a hemólise figura 3 (B) 5 minutos e em (C) 10 minutos.

Posteriormente foi realizada uma varredura por espectrofotometria no UV-Vis para o extrato bruto hidroetanólico da resina de $P$. spruceanum entre os comprimentos de ondas de 300 a $800 \mathrm{~nm}$, como pode ser observado no (Figura 1).
Observam-se no Gráfico 1, bandas nas faixas entre 365 a $424 \mathrm{~nm}$ características de absorção de fenóis e cumarinas, em 434 a 462 nm, e entre 467 a $503 \mathrm{~nm}$ características da absorção para compostos flavonólicos.

A partir dos resultados anteriores de fitoquímica observados na tabela 2 , é possível sugerir através do espectro de varredura entre 800 a $300 \mathrm{~nm}$ por absorbância, a presença de compostos do tipo fenólicos, cumarínicos e flavonólicos (Figura 1). Inúmeros trabalhos avaliam por espectroscopia no UV-Vis a través de varreduras sendo possível presumir a presença de determinadas classes fitoquímicas. Outros trabalhos aplicando esta técnica foram descritas por García et al. (2019) onde também encontraram bandas entre 200 a $300 \mathrm{~nm}$ correspondente a classe de compostos fenólicos e entre 400 a $500 \mathrm{~nm}$ para compostos flavonólicos, avaliando as frações e o extrato aquoso de Anacardium occidentale.

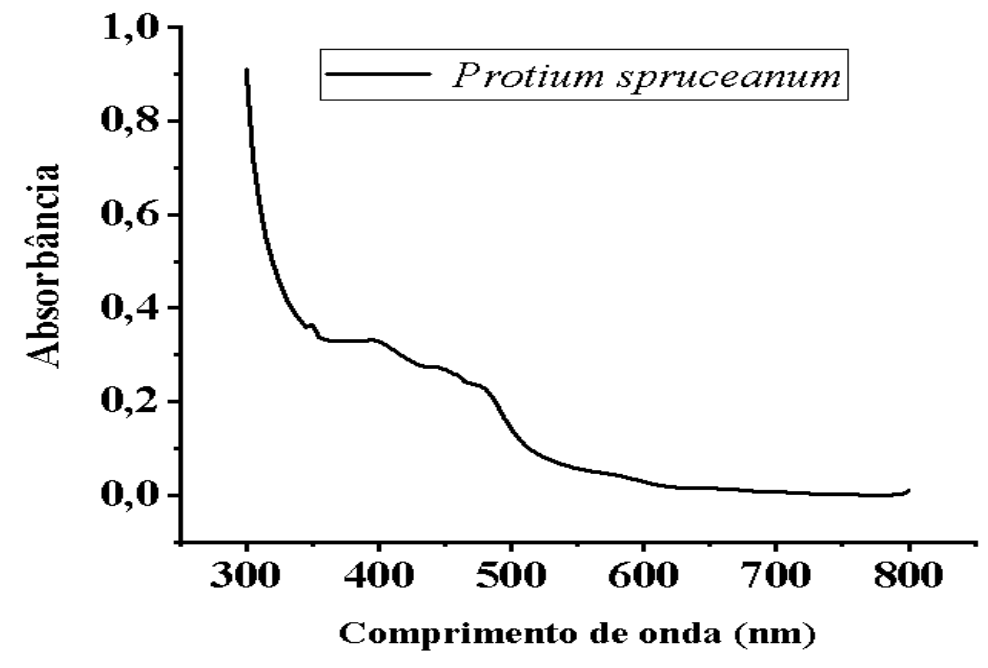

Figura 1 - Espectro de varredura do extrato bruto hidroetanólico de $P$. spruceanum. Fonte: Própria (2020).

Souza et al. (2018) avaliaram o fruto de Bacteris gasipaes (pupunha) onde encontraram compostos flavonólicos no extrato etanólico da casca com duas bandas entre 260 e $290 \mathrm{~nm}$ e em 400 e 490 nm. Já Fuentes et al. (2017), os pesquisadores analisaram por espectroscopia UV-Vis para os extratos da folha, galhos e raízes de Macroptilium lathyroides onde encontraram bandas em 375, $384,386,390$ e $392 \mathrm{~nm}$ que evidenciam a presença de compostos cumarínicos, e em $207 \mathrm{~nm}$ para alcalóides. Conforme Bobin et al. (1994), os flavonoides apresentam duas bandas no espectro de absorção UV-Vis em 240 a 280 e 300 a 550 nm

Na Tabela 3 estão apresentados os resultados da atividade de inibição observados pela formação de halo de antibiose para $S$. aureus, $S$. sorovar Typhimurium, S. sorovar Enteritidis e E. coli sobre o extrato hidroetanólico da resina de $P$. spruceanum e comparados aos controles positivos e negativo. 
Tabela 3 - Atividade antibacteriana avaliada pela formação de halo de antibiose expresso em $(\mathrm{mm})$ para o extrato de $P$. spruceanum $20 \%(\mathrm{~m} / \mathrm{v})$ frente a S. aureus, S. Typhimurium, S. Enteritidis e E. coli.

\begin{tabular}{lc}
\hline \multicolumn{1}{c}{ Microrganismos } & Diâmetro do halo $(\mathbf{m m})$ \\
\hline S. aureus & $19,13 \pm 0,06 \mathrm{~mm}$ \\
S. Typhimurium & $14,07 \pm 0,12 \mathrm{~mm}$ \\
S. Enteritidis & $17,51 \pm 0,04 \mathrm{~mm}$ \\
E. coli & $9,18 \pm 0,08 \mathrm{~mm}$ \\
*Ciprofloxacina & $29 \pm 0,03 / 27 \pm 0,08 / 30 \pm 0,09 / 29 \pm 0,12 \mathrm{~mm}$ \\
*Azitromicina & $27 \pm 0,12 / 31 \pm 0,06 / 29 \pm 0,09 / 28 \pm 0,11 \mathrm{~mm}$ \\
Água & + \\
\hline *Antibióticos de referência na dosagem de $500 \mathrm{mg} \mathrm{mL}^{-1}$, como controles positivos. Os respectivos resultados são apresentados em mé- \\
dias a partir de três repetições expressos em $(\mathrm{mm})$ seguidos de $( \pm)$ desvio padrão. Cada (/) representa a média do halo de antibiose para \\
cada cepa bacteriana referente ao extrato de $P$. spruceanum e respectivos controles positivos (antibióticos de referência). Controle nega- \\
tivo água $(+)$ para crescimento de todos os isolados bacterianos.
\end{tabular}

Conforme se observa na tabela 3, o extrato hidroetanólico da resina de $P$. spruceanum apresentou boa e especial eficiência de inibição através do ensaio de antibiose para $S$. aureus, S. Typhimurium e $S$. Enteritidis com halos superiores a $10 \mathrm{~mm}$. Já para E. coli, o isolado bacteriano apresentou baixa sensibilidade ao extrato, apresentando resultado inferior a $10 \mathrm{~mm}$. Possivelmente os compostos agindo por sinergismo não possuem eficiência com alta eficácia para inibir o crescimento desta cepa resistente.

No estudo desenvolvido por Amparo et al. (2018), onde avaliaram o extrato etanólico dos galhos de $P$. spruceanum, os pesquisadores obtiveram importante atividade antibacteriana para $S$. aureus e S. aureus MRSA, Staphylococcus saprophyticus, Enterococcus faecalis e S. Enteritidis. Em outro estudo realizado também por Amparo (2016), o pesquisador encontrou atividade de inibição para o extrato bruto das folhas e galhos de $P$. spruceanum, avaliando isolados de $S$. aureus com halo de inibição igual a 18,52 e 18,89; 18,52 e 18,89 ; e de 21,03 e $21,65 \mathrm{~mm}$ e para $E$. coli de 10,$52 ; 10,17$ e de $10,08 \mathrm{~mm}$ respectivamente, superiores aos resultados deste estudo. Já para a cepa de S. Typhimurium com inibição de 10,12 e de $10,67 \mathrm{~mm}$, e para $S$. Enteritidis de 11,11 e de $13,50 \mathrm{~mm}$, os resultados foram inferiores ao teste de antibiograma deste estudo, que demonstraram maior sensibilidade pelo extrato hidroetanólico da resina dos galhos e raízes.

Outra espécie do gênero Protium, o Protium heptaphyllum apresentou em estudo, atividade antimicrobiana para fungos dos gêneros Candida, isolado C. krusei e para Cryptococcus, isolado $C$. neoformans e para a bactéria do gênero Staphylococcus, isolado de $S$. aureus através do extrato etanólico da casca da mesma espécie vegetal (Violante et al., 2012). Já no estudo de Suárez et al. (2007), os investigadores avaliaram a espécie Protium neglectum endêmica na Venezuela, onde o óleo essencial extraído da resina apresentou atividade bactericida para cepas de Bacillus subtillis e S. aureus.

De acordo com Matikainen et al. (2015), Wang et al. (2015), Alves et al. (2014), Aderogba et al. (2013) e Johann et al. (2007), a excepcional atividade antimicrobiana apresentada para $P$. spruceanum, está relacionada aos compostos linoleato de metila, amirina, catequina, procianidina e quercetina.

Comparando com outros extratos vegetais na literatura, Fuentes et al. (2017) encontraram excepcional atividade antibacteriana em extratos a $20 \%$ das folhas, galhos e raízes de $M$. lathyroides. Os pesquisadores observaram halos de inibição de 8 e $11 \mathrm{~mm} \mathrm{~S}$. aureus e de 8 e $14 \mathrm{~mm}$ para E. coli nos extratos das folhas (tintura e seca), e de 8 a $10 \mathrm{~S}$. aureus e de 9 e $11 \mathrm{~mm}$ para E. coli $\mathrm{mm}$ nos extratos dos galhos (tintura e seca), e de 8 a $11 \mathrm{~mm} S$. aureus e de 8 e $15 \mathrm{~mm}$ E. coli para os extratos das raízes (tintura e seca). Não foi observada inibição para o isolado de Pseudomonas aeruginosa em nenhum dos extratos avaliados pelos pesquisadores. Como controle positivo foi utilizado ciprofloxacina e gentamicina com inibição de 24,27 e $14 \mathrm{~mm}$ para $S$. aureus, E. coli e $P$. aeruginosa.

\section{CONCLUSÕES}

O extrato hidroetanólico da resina extraída das raízes descobertas e do tronco de indivíduos de Protium spruceanum apresentam importantes resultados, tanto para as avaliações fitoquímicas, físico-químicas em especial para atividade antioxidante na redução do modelo de radical livre DPPH, bem como, no ensaio de antibiograma realizado para as quatro estirpes bacterianas resistentes a antibióticos.

Trabalhos futuros deverão ser realizados avaliando as mesmas características, bem como determinar a capacidade de inibição mínima 
(CIM) das bactérias, e testar sobre alguns isolados fúngicos que causam sérios problemas de saúde pública como o gênero Candida, bem como, cepas fitopatológicas que causam perdas agrícolas anualmente em plantações pelo mundo.

\section{AGRADECIMENTOS}

Ao Instituto Federal Goiano, Campus Rio Verde; aos laboratórios de Química Tecnológica, Águas e Efluentes, Bioensaios e Biomoléculas, Sistemática Vegetal, Materiais e Eletroanalítica, e de Fisiologia Vegetal; ao Herbário do IF Goiano; a Central Analítica Multi-Usuário - CEMA; aos órgãos de fomento em pesquisa, CAPES, CNPq e FINEP.

\section{REFERÊNCIAS BIBLIOGRÁFICAS}

Aderogba MA, Ndhlala AR, Rengasamy KRR, Van Staden J. Antimicrobial and selected in vitro enzyme inhibitory effects of leaf extracts, flavonols and indole alkaloids isolated from Croton menyharthi. Molecules, v. 18, n. 10, p. 12633-12644, 2013. https://doi.org/10.3390/molecules181012633

Adfa M, Hattori Y, Ninomiya M, Funahashi Y, Yoshimura T, Koketsu M. Chemical constituents of Indonesian plant Protium javanicum Burm. f. and their antifeedant activities against Coptotermes formosanus Shiraki. Journal Natural Product Research, v. 27, n. 3, 270-273, 2013. https://doi.org/10.1080/14786419.2012.665917

Alarcón MET, Conde CG, Méndez GL. Extracción, caracterización y actividad antioxidante del aceite esencial de $E u$ calyptus globulus Labill. Revista Cubana de Farmacia, 52(1), p. e266, 2019. https://www.medigraphic.com/cgibin/new/resumenI.cgi?IDARTICULO=93927

Alves MM, Pereira AMS, Pereira PS, França SC, Bertoni BW. Caracterização química de tinturas e extratos secos de plantas medicinais do Cerrado por cromatografia em camada delgada. Scientia Plena, v. 7, n. 12, p. 9901, 2011. https://scientiaplena.emnuvens.com.br/sp/article/view/159

Alves CT, Ferreira ICFR, Barros L, Silva S, Azeredo J, Henriques M. Antifungal activity of phenolic compounds identified in flowers from North Eastern Portugal against Candida species. Future Microbiology, v. 9, p. 139-146, 2014. https://doi.org/10.2217/fmb.13.147

Amparo TR. Análise fitoquímica e Bioprospecção para atividade antimicrobiana de Protium spruceanum (Benth.) Engler. 2016. 151 p. Dissertação (Mestrado em Ciências Farmacêuticas) - Universidade Federal de Ouro Preto, Minas Gerais.

Amparo TR, Rodrigues IV, Seibert JB, Souza RHZ, De Oliveira AR, Cabral VAR, Vieira PMA, Brandão GC, Okuma AA, Filho SAV, Teixeira LFM, De Souza GHB. Antibacterial activity of extract and fractions from branches of Protium spruceanum and cytotoxicity on fibroblasts. Natural Product Research, v. 32, n. 16, p. 1951-1954, 2018. https://doi.org/10.1080/14786419.2017.1354182
Bobin MF, Raymond M, Martini MC. UVA/UVB absorption properties of natural products. Cosmetic and Toiletries, v. 109, n. 11, p. 63-70, 1994.

Conde CG, Alarcón MET, Parajo NP, Llamas EG, Méndez GL. Caracterización química y determinación de la actividad antioxidante de la pulpa de Tamarindus indica L. (tamarindo). Revista Cubana de Plantas Medicinales, v. 22, n. 2, 2017.

http://revplantasmedicinales.sld.cu/index.php/pla/article/vi ew/509

Conde CG, Pajaro NP, Méndez GL. Actividad antioxidante y contenido fenólico del extracto etanólico de Capsicum annum L. Revista Cubana de Farmacia, v. 52, n. 2, p. e78, 2019. http://revfarmacia.sld.cu/index.php/far/article/view/78

Conde CG, Guardo KPT, Llamas EG, Pájaro-Castro NP, Milano YG. Caracterización química y evaluación de la actividad antioxidante de la pulpa de Passiflora edulis Sims. (gulupa). Revista Cubana de Plantas Medicinales, v. 22, n. 2, 2017.

http://www.revplantasmedicinales.sld.cu/index.php/pla/arti cle/view/513

Dacie JV, Lewis SM, Catovsky D. Blood cell cytochemistry and supplementary techniques. Practical Hematology, Churchill Livingstone, Edinburgh, 120-148 p. 1975.

Domínguez OGP, Pesantes KEB, Martínez MM, Gaitén YG. Estudio químico y evaluación biológica del extracto etanólico de Allium schoenoprasum L. Regel \& Tiling (Cebollín). Revista Cubana de Farmacia, v. 52, n.1, p. e98, 2019. http://revfarmacia.sld.cu/index.php/far/article/view/98

Farjado CG, Vieira FA, Morais FM, Maracajá PB, De Carvalho D. Polimorfismo de isoenzimas em Protium spruceanum (Benth.) Engler (Burseraceae) com base para estudos de diversidade genética. Revista Verde de Agroecologia e Desenvolvimento Sustentável, v. 4 n. 4, p. 27-32, 2009. https://editoraverde.org/gvaa.com.br/revista/index.php/RV ADS/article/viewFile/213/213

Fernández MC, Fárez DLA, Roblez NCC, Hernández IM, Galván DSM, Rubio OC. Composición química y actividad antimicrobiana del extracto etanólico de las partes aéreas de Minthostachys mollis Griseb. Revista Cubana de Farmacia, v. 51, n. 2, 2017. http://revfarmacia.sld.cu/index.php/far/article/view/221

Flores López ZY, Díaz APC, Santos EHQ, Gaitén YG, Olivet ES, Cuellar AC. Características fitoquímicas y toxicológicas de la semilla Swietenia humilis Zuccarini y su efecto hipoglucemiante. Revista Cubana de Farmacia, v. 52, n. 1, p. e129, 2019. https://www.medigraphic.com/cgibin/new/resumen.cgi?IDARTICULO=93929

Fuentes JTL, Fuentes DP, Herrera GC. Actividad antibacteriana in vitro de los extractos y de las tinturas al $20 \%$ de Macroptilium lathyroides (L.) Urban (maribari). Revista Cubana de Plantas Medicinales, v. 22, n. 4, 2017. http://www.revplantasmedicinales.sld.cu/index.php/pla/arti cle/view/627

García, J. H. G., Naranjo, B. D. C., Salazar, M. T. J., \& Serna, D. M. O. (2019). Actividad antibacteriana y antifúngica de los extractos de diferente polaridad de Anacardium occidentale. Revista Cubana de Plantas Medicinales, 24(2), e677. 
http://revplantasmedicinales.sld.cu/index.php/pla/article/vi ew/677

Johann S, Soldi C, Lyon JP, Pizzolatti MG, Resende MA. Antifungal activity of the amyrin derivatives and in vitro inhibition of Candida albicans adhesion to human epithelial cells. Letters in Applied Microbiology, v. 45, n. 2, p. 148-153, 2007. https://doi.org/10.1111/j.1472765X.2007.02162.x

Lemes EO, Fernandes MMC, Rosa VP, Nascimento AH. Levantamento da utilização do pequi (Caryocar brasiliense Camb.) como agente antioxidante na prevenção de doenças neurodegenerativas. Uniciências, v. 21, n. 2, p. 110-114, 2017. https://doi.org/10.17921/1415

$5141.2017 \mathrm{v} 21 \mathrm{n} 2 \mathrm{p} 110-114$

Machado LB, Zoghbi MGB, Andrade EHA. Seasonal variation in the composition of the essential oils from the leaves, thin branches and resin of Protium spruceanum (Benth.) Engl. Flavour and Fragrance Journal, v. 18, n. 4, p. 339-341, 2003.

Magalhães A, Zoghbi MDGB, Siani, AC. 5-

Methoxypropacin, a novel coumarinolignoid from Protium unifoliolatum. Journal Natural Product Research, v. 20, n. 1, p. 43-46, 2006.

https://doi.org/10.1080/14786410500055555

Menezes Filho ACP, Castro CFS. Análise fitoquímica preliminar de extratos foliares de Orchidaceas (Cattleya walkeriana Gardner.), (Encyclia linearifolioides Kraenzl.) e (Polystachya concreta (Jacp.) Garay \& H. R. Sweet). Ensaios e Ciências, v. 23, n. 1, p. 16-23, 2019.

https://doi.org/10.17921/1415-6938.2019v23n1p16-23

Matikainen J, Lehtinen M, Pelttari E, Elo H. Toxicity of fatty acid autoxidation products: highest anti-microbial toxicity in the initial oxidative phase. Molecules, v. 20, n. 1, p. 3542, 2015. https://doi.org/10.3390/molecules20010035

Nofiani R, Kurniadi R, Ardiningsih P. Antimicrobial, antioxidant, hemolytic activities and toxicity of ethyl acetate extract from an unidentified coral-associated Fungus, Aspergillus brevipes RK06. Indonesian Journal of Cancer Chemoprevention, v. 2, n. 2, p. 212-216, 2011. http://dx.doi.org/10.14499/indonesianjcanchemoprev2iss2p p212-216

Oliveira AKM, Pereira KCL, Muller JAI, Matias R. Análise fitoquímica e potencial alelopático das cascas de Pouteria ramiflora na germinação de alface. Horticultura Brasileira, v. 32, p. 41-47, 2014. https://doi.org/10.1590/S010205362014000100007

Oliveira Filho AT, Ratter JA. A study of the origin of central Brazilian forests by the analysis of the plant species distribution. Edinburgh Journal of Botany, v. 52, n. 2, p. 141194, 1995.

Pessuto MB, Da Costa IC, De Souza AB, Nicoli FM, De Mello JCP, Petereit F, Luftmann H. Atividade antioxidante de extratos e taninos condensados das folhas de Maytenus ilicifolia Mart. ex Reiss. Química Nova, v. 32, n. 2, p. 412 416, 2009. https://doi.org/10.1590/S010040422009000200027

Ramos RM, Feitosa JM, Lima VS, Santos RC, De Oliveira AM, Soares LAL, Da Silva GC. Estudo comparativo da composição fitoquímica, citotoxicidade e potencias antioxidante e fotoprotetora da casca e folha de Erythrina velu- tina. Brazilian Journal of Development, v. 6, n. 6, p. 33140-33158, 2020. https://doi.org/10.34117/bjdv6n6-026

Rodrigues IMC, Souza Filho APS, Ferreira FA. Estudo fitoquímico de Senna alata por duas metodologias. Revista Planta Daninha, v. 27, n. 3, p. 507-513, 2009. https://doi.org/10.1590/S0100-83582009000300011

Simões RC, De Almeida SSMS. Estudo fitoquímico de Bauhinia forficata (Fabaceae). Biota Amazônia, v. 5, n. 1, p. 27-31, 2015. http://dx.doi.org/10.18561/21795746/biotaamazonia.v5n1p27-31

Souza BAS, Souza FBS, Prado AF, Almeida LD, Amarante CB. Avaliação in vitro da atividade fotoprotetora de extratos vegetais da Amazônia. In: $58^{\circ}$ Congresso Brasileiro de Química, São Luís-MA, 6 a 9 de novembro de 2018, 2018.

Sousa IJO, Silva MCP, Leopoldino GL, Agostinho LS. Estudo fitoquímico, avaliação da capacidade hemolítica e antimicrobiana de um extrato bruto da casca do caule de $\mathrm{Zi}$ ziphus joazeiro Mart. (Rhamnaceae). Journal of Biology \& Pharmacy and Agricultural Management, v. 14, n. 4, p. 208-225, 2018.

http://revista.uepb.edu.br/index.php/biofarm/article/view/3 496

Suaréz AI, Compagnone RS, Acosta D, Vásquez L, Diaz B, Canelón DJ. Chemical composition and antimicrobial activity of the essential oil from oleoresins of Protium neglectum. Journal of Essential Oil Bearing Plants, v. 10, n. 1, p. 70-75, 2007. https://doi.org/10.1080/0972060X.2007.10643521

Sultana B, Anwar F, Ashraf M. Effect of extration solvent/technique on the antioxidant activity of selected medicinal plant extracts. Molecules, v. 14, p. 2167-2180, 2009. https://doi.org/10.3390/molecules 14062167

Vieira FA, Appolinário V, Fajardo CG, De Carvalho D. Reproductive biology of Protium spruceanum (Burseraceae), a dominant dioecious tree in vegetation corridors in Southeastern Brazil. Brazilian Journal of Botany, v. 33, n. 4, p. 711-715, 2010. https://doi.org/10.1590/S010084042010000400018

Vieira FA, Carvalho D. Genetic structure of na insectpollinated and Bird-dispersed tropical tree in vegetation fragments and corridors: implication for conservation. Biodiversity and Conservation, v. 17, p. 2305-2321, 2008. https://doi.org/10.1007/s10531-008-9367-7

Violante IMP, Hamerski L, Garcez WS, Batista AL, Chang MR, Pott VJ, Garcez FR. Antimicrobial activity of some medicinal plants from the cerrado of the central-western region of Brazil. Brazilian Journal of Microbiology, v. 43 , n. 4, p. 1302-1308, 2012. https://doi.org/10.1590/S151783822012000400009

Zimmermann AM, Kirsten VR. Alimentos com função antioxidante em doenças crônicas: Uma abordagem clínica. Revista Eletrônica Disciplinarum Scientia, Ciências da Saúde, v. 9, n. 1, p. 51-68, 2008. https://periodicos.ufn.edu.br/index.php/disciplinarumS/arti cle/view/934

Wang C-M, Hsu Y-M, Jhan Y-L, Tsai S-J, Lin S-X, Su C-H, Chou C-H. Structure elucidation of procyanidins isolated from Rhododendron formosanum and their anti-oxidative and anti-bacterial activities. Molecules, v. 20, n. 7, p. 
12787-12803, 2015.

https://doi.org/10.3390/molecules200712787 